\title{
UMA ANÁLISE DA INFLUÊNCIA DA IMAGEM DA LOJA, MARCA DO VAREJISTA E QUALIDADE PERCEBIDA NA SATISFAÇÃO DOS CONSUMIDORES NO VAREJO SUPERMERCADISTA
}

\author{
CERIBELI, Harrison Bachion ${ }^{1}$ \\ MERLO, Edgard Monforte ${ }^{2}$ \\ MORAES, Patrícia Sedlacek ${ }^{3}$
}

RESUMO: Este artigo teve como objetivo avaliar a satisfação de consumidores no varejo supermercadista, analisando de forma integrada a influência da qualidade percebida, imagem da loja e marca do supermercado. Para atingir tal objetivo, foi realizado um levantamento de campo na cidade de Ribeirão Preto, com uma amostra de 235 pessoas. Deve-se destacar que, por meio da análise estatística dos dados coletados, foi possível confirmar a importância conjunta da imagem da loja, da marca do supermercado e da qualidade percebida para a formação da satisfação dos consumidores no segmento de varejo estudado. A importância deste estudo reside no fato de que as constatações aqui desenvolvidas vêm ao encontro de pesquisas recentes, citadas no referencial teórico do trabalho, que analisam o conceito de experiências de consumo, no qual a satisfação do consumidor no varejo é formada por diversos elementos simultaneamente, dentre eles imagem, marca e qualidade percebida.

Palavras-chave: Imagem da loja. Marca do supermercado. Qualidade percebida. Satisfação. Supermercados.

SUMMARY: This article aims to evaluate the satisfaction of consumers in the supermarket retail, by analyzing the integrated influence of perceived quality, store image and brand of the supermarket. To achieve this goal, we performed a survey in the city of Ribeirao Preto, with a sample of 235 people. It should be noted that, through statistical analysis of data collected, it was possible to confirm the importance of image of the store, supermarket brand and perceived quality for the formation of consumer satisfaction in the retail segment studied. The importance of this study lies in the fact that the findings developed here are similar to recent research, which examined the concept of consumer experiences, in which customer satisfaction in retail depends of several elements simultaneously, including image, brand and perceived quality.

Keywords: Store image. Supermarket brand. Perceived quality. Satisfaction. Supermarkets.

\section{INTRODUÇÃO}

No cenário moderno, a competição torna-se cada vez mais acirrada; mais concorrentes surgem em um mercado altamente globalizado, no qual a velocidade das mudanças acaba por influenciar as expectativas e necessidades dos consumidores, que têm hoje um grande número de opções de lojas e produtos concorrentes, ao mesmo tempo em que, mais informados, exigem desempenhos cada vez melhores das empresas que atuam no mercado.

Há inúmeros fatores que influenciam as decisões de compra dos consumidores, sendo a satisfação um dos elementos mais importantes neste tipo de decisão. Yi (1989) afirma que a satisfação do consumidor influencia a intenção de compra e a atitude após a compra, tornando-se extremamente importante para os varejistas a mensuração dos elementos que compõem esta satisfação, e, consequentemente, que influenciam na escolha do consumidor dentre um conjunto de opções de lojas varejistas.

Segundo Verhoef et al. (2009), um dos aspectos mais relevantes para a formação da satisfação dos

\footnotetext{
${ }^{1}$ Doutorando em Administração pela FEARP/USP. Mestre em Administração pela FEARP/USP.

${ }^{2}$ Livre-docente em Administração pela FEARP/USP. Doutor em Administração pela FEA/USP.

${ }^{3}$ Graduada em Administração pela FEARP/USP.
} 
varejistas está relacionado ao conceito de experiências de consumo, tema este que, segundo o mesmo autor, ainda se encontra pouco explorado na academia. Neste sentido, mais pesquisas voltadas para este tema devem ser incentivadas, já que tendem a contribuir para a formação de um referencial teórico acerca de um assunto bastante inexplorado e recente no marketing de varejo moderno (VERHOEF et al., 2009).

Grewal; Levy; Kumar (2009) explicam que as experiências de consumo no varejo são influenciadas por todos os pontos de contato entre o varejista e o consumidor, tornando-se extremamente importante o estudo de cada um destes pontos de interação.

Neste trabalho, foram abordados três elementos das experiências de consumo no varejo: a imagem da loja, a marca do varejista e a qualidade percebida pelos consumidores. Além disso, para limitar o escopo da pesquisa, foi delimitado para o estudo o segmento varejista de supermercados, já que este é um dos mais importantes formatos de varejo de alimentos no Brasil na atualidade (MOURA; SILVA; VIANA, 2005).

O objetivo desta pesquisa foi avaliar a satisfação de consumidores supermercadistas de Ribeirão Preto, analisando de forma integrada a influência da qualidade percebida, imagem da loja e marca do supermercado para a formação desta satisfação.

A importância deste trabalho reside no fato de que o tema experiências de consumo ainda é pouco explorado na academia (VERHOEF et al., 2009), sendo que esta pesquisa contribui para a formação de uma visão mais sistêmica da satisfação do consumidor no varejo, integrando diversos conceitos ligados às experiências de compra neste segmento de mercado.

\section{REFERENCIAL TEÓRICO}

\subsection{VAREJO SUPERMERCADISTA}

Segundo Parente (2009, p.22), o "varejo consiste em todas as atividades que englobam o processo de venda de produtos e serviços para atender a uma necessidade pessoal do consumidor final".

Já Levy; Weitz (2000, p. 27) enfatizam a questão da entrega de valor aos consumidores ao definirem varejo como "um conjunto de atividades de negócios que adiciona valor a produtos e serviços vendidos aos consumidores para seu uso pessoal e familiar".

Finalmente, Kotler; Keller (2006) destacam que os varejistas têm a maior parte de seu faturamento proveniente da venda de pequenos lotes para os consumidores finais.

Neste sentido, é possível perceber a importância do setor varejista na economia, na medida em que é responsável por intermediar o comércio entre os fabricantes e os consumidores no final da cadeia produtiva.

Parente (2009) afirma que os varejistas devem gerenciar uma série de elementos que fazem parte de seu composto de marketing, de modo a maximizar a satisfação de seus clientes. Para Levy; Weitz (2000), o composto de varejo pode ser definido como uma combinação de fatores que os varejistas devem usar buscando satisfazer as necessidades dos clientes e influenciar suas decisões de compra.

Os elementos do composto de varejo que devem ser gerenciados pelos varejistas são o mix e os tipos de mercadoria e serviços oferecidos, preços, publicidade e programas promocionais, design de lojas e exposição das mercadorias, assistência aos consumidores oferecida pelos vendedores e localização da loja (LEVY; WEITZ, 2000).

De acordo com Las Casas (2007), existem vários formatos de lojas varejistas. Rojo (1998) explica que diversos fatores influenciam as tendências dos formatos de lojas de varejo, dentre eles as características familiares, os avanços tecnológicos, as mudanças na conservação e preparo de alimentos e 
alguns aspectos macroeconômicos que interferem na ida do cliente aos pontos-de-venda.

No que tange o varejo de alimentos, Moura, Silva e Viana (2005) afirmam que os principais formatos são os hipermercados, supermercados, lojas de especialidades (por exemplo, açougue e padarias), mercearias e feiras livres, destacando-se os supermercados.

Parente (2009), Saab e Gimenez (2000), Alexander e Silva (2002), Levy; Weitz (2000), Rojo (1998); Czinkota (2001) explicam que o varejo supermercadista é composto por lojas que adotam o autoserviço, disponibilizando para os clientes uma variedade de itens entre 4.000 e 14.000, alimentícios ou não, com no mínimo dois check-outs e área útil variando entre 300 e $5.000 \mathrm{~m} 2$. Segundo estes mesmos autores, os supermercados ainda são caracterizados pela não presença de vendedores durante o processo de compras.

De acordo com o $32^{\circ}$ Ranking Abras 2009, as vendas do setor supermercadista brasileiro representaram 5,5\% do Produto Interno Bruto do país. Além disso, o relatório divulgado pela ABRAS (Associação Brasileira de Supermercados) aponta que o faturamento do setor supermercadista brasileiro em 2008 alcançou R \$ 158,5 bilhões, representando um aumento real de 10,5\% e nominal de 16,3\% em relação a 2007. Também se deve ressaltar que, em 2008, o número de lojas chegou a 75.725 pontos (aumento de 1,5\% em relação a 2007), com 876.916 funcionários (crescimento de 1\% em relação a 2007) e lucro líquido médio de 2,12\% sobre o faturamento (o maior lucro líquido do setor deste 1999, quando o relatório começou a ser divulgado).

A crescente importância deste formato de varejo foi destacada por uma pesquisa feita por Moura; Silva; Viana (2005), concluindo que o hiper/supermercado tem ganhado a preferência do consumidor para a compra de produtos alimentares em detrimento dos formatos tradicionais, como, por exemplo, açougues e feiras livres, já que os supermercados possuem geralmente alta variedade de produtos, voltada principalmente para o comércio de alimentos.

$\mathrm{O}$ varejo supermercadista tem enfrentado mudanças constantes, incorporando em sua estratégia o auto-serviço, a modernização das lojas, melhor mix de produtos e melhor nível de produto, sempre visando à satisfação da necessidade de comodidade e independência do consumidor no momento da compra (SILVA, 2009).

Entre as mudanças atuais, cabe destacar, conforme Santos; Gimenez (1999), a realização de parcerias entre supermercados e fornecedores e a realização de contratos de fornecimento de longo prazo, sendo que esta parceria abrange a reposição de produtos com funcionários próprios da indústria, o compartilhamento de informações para lançamento de novos produtos ou para promoções, a definição junto ao varejista da colocação dos produtos nos supermercados, o monitoramento do nível de estoques sendo desenvolvido pelos próprios fabricantes, a fabricação de produtos destinados às marcas próprias, entre outras.

Além disso, cabe destacar as recentes mudanças no foco de operações da cadeia de suprimentos moderna, que engloba basicamente os produtores, os varejistas e os consumidores. No período inicial da manufatura, a decisão a respeito dos produtos e serviços a serem oferecidos aos consumidores era tomada pelos fabricantes. No entanto, com o aumento da importância do varejo na economia, a decisão acerca do mix de vendas passou a se concentrar nos varejistas. Mais recentemente, devido ao aumento da demanda por produtos e dos estudos do comportamento do consumidor, o consumidor passou a ser o elo mais importante da cadeia de fornecimento do varejo, ditando as tendências dos produtos e serviços a serem oferecidos (ENGEL; BLACKWEL; MINIARD, 2005).

Sendo assim, torna-se essencial entender como o consumidor percebe suas experiências de consumo no varejo supermercadista e como gerenciar os elementos que influenciam estas experiências, de maneira a aumentar sua satisfação. 


\subsection{SATISFAÇÃO DO CONSUMIDOR E EXPERIÊNCIAS DE CONSUMO}

A satisfação do consumidor é decorrente de uma avaliação pós-consumo feita pelos consumidores, comparando o que era esperado e o que foi recebido no momento da compra (ENGEL; BLACKWEL; MINIARD, 2005).

De maneira semelhante, Kotler; Keller (2006) afirmam que satisfação é a medida de prazer ou desapontamento resultante da diferença entre o desempenho esperado e o percebido pelo cliente. Além disso, estes autores afirmam que os clientes procuram sempre maximizar o valor no processo de compra levando em conta os custos envolvidos e os limites de conhecimento, mobilidade e renda.

Para Oliver (1997), o conceito de satisfação apresenta um papel central na literatura de Marketing. Este autor define satisfação como a resposta ao contentamento do consumidor, ou seja, um julgamento realizado pelo consumidor do nível prazeroso de contentamento que um produto ou serviço ofereceu ou está oferecendo.

Em uma pesquisa realizada para analisar as consequências da satisfação em relação à lealdade dos consumidores, Larán; Espinoza (2004) concluíram que há uma relação positiva entre clientes satisfeitos e lealdade, ou seja, clientes satisfeitos tendem a ser mais leais. Por isso, destaca-se a necessidade das empresas de medir sistematicamente a satisfação do cliente e os aspectos que a influenciam (KOTLER; KELLER, 2006).

Neste sentido, torna-se fundamental estudar as experiências de consumo dos clientes supermercadistas, já que, conforme defendem Grewal; Levy; Kumar (2009); Verhoef et al. (2009), as experiências de consumo têm influência direta na satisfação dos consumidores no varejo.

Grewal; Levy; Kumar (2009) salientam que, na administração de varejo moderna, não basta apenas focar em preços baixos e produtos inovadores, na medida em que o acirramento da competição neste setor tem forçado os varejistas a repensarem suas estratégias competitivas, sendo necessário incorporar, nestas estratégias, ações voltadas para a criação de experiências de consumo agradáveis para os clientes.

De acordo com Meyer; Schwager (2007), as experiências de consumo podem ser traduzidas como respostas internalizadas e subjetivas dos consumidores relacionadas a qualquer contato desenvolvido com uma empresa.

Segundo Gentile, Spiller; Noci (2007), uma experiência de consumo é o resultado de um conjunto de interações entre um indivíduo e um produto, serviço ou empresa, provocando uma reação neste indivíduo. Estes autores ainda explicam que as experiências de consumo podem afetar os clientes nos níveis racional, emocional, espiritual, físico e sensorial, dependendo das interações e do envolvimento do consumidor.

Para Grewal; Levy; Kumar (2009), as experiências de consumo englobam cada ponto de contanto que envolva interação entre o cliente e a empresa, produto ou serviço. Estes autores propõem um modelo para explicar o conceito de experiências de consumo, no qual estas são afetadas por macro-fatores, tais como aspectos sócio-econômicos que afetam o nível de renda e poupança dos indivíduos, e por fatores que podem ser controlados pelas empresas varejistas, incluindo comunicação, preços, sortimento de mercadorias, localização, e fatores relacionados à cadeia de suprimentos, como conflitos de pontos-devendas.

Neste artigo, são analisados três aspectos que influenciam as experiências de consumo no varejo supermercadista: a imagem do varejista e a marca do supermercado, que fazem parte da comunicação desenvolvida pelo varejista, e a qualidade percebida pelos consumidores, relacionada ao sortimento de mercadorias e serviços disponibilizado pelo varejista. 


\subsection{QUALIDADE PERCEBIDA}

A qualidade geral percebida pode estar relacionada com a qualidade percebida do produto e com a qualidade percebida do serviço. A qualidade do produto está relacionada com fatores intrínsecos, ou seja, características do produto em si, como cor e sabor, e com fatores extrínsecos, como embalagem, preço e propaganda. A qualidade do serviço, cuja mensuração é mais difícil por ser predominantemente intangível e perecível, conta com atributos extrínsecos para sua avaliação (SCHIFFMAN; KANUK, 2000).

De acordo com Zeithaml (1988), qualidade está relacionada com o julgamento do consumidor sobre a excelência global ou superioridade de um produto ou serviço.

Segundo um estudo realizado por Sirohi et al. (1998), a qualidade de serviços é o mais crítico determinante de percepção de qualidade no varejo. De acordo com Rojo (1998), em um supermercado, além da qualidade dos produtos comercializados pela loja, é fundamental a qualidade dos serviços para conquistar a satisfação dos consumidores.

O conjunto de serviços que pode ser oferecido no varejo é extenso e engloba a qualidade de atendimento, opções e facilidade de pagamento, disponibilidade de crédito, rapidez no atendimento e tempo de espera em fila, horários de funcionamento, além de outros serviços como política de devolução e troca, disponibilidade de estacionamento, presença de empacotadores, entre outros. (McGOLDRICK, 2000).

Devido à elevada importância da qualidade de serviços, diversos autores desenvolveram métodos para sua mensuração. O método mais conhecido é o Servqual, desenvolvido por Berry; Zeithaml; Parasuraman (1990), em um estudo que buscou investigar os conceitos envolvendo qualidade de serviços. Estes autores descreveram as cinco principais dimensões como tangíveis (equipamentos e instalações), confiabilidade (conformidade na prestação dos serviços e resolução de problemas), responsividade (prontidão para ajudar os clientes), segurança (tanto a empresa quanto os funcionários devem transmitir segurança para os clientes) e empatia (atendimento individual e atencioso).

Johnson; Tsiros; Lancioni (1995) propuseram um modelo ampliado de avaliação, que utiliza a teoria dos sistemas para analisar a qualidade dos serviços oferecidos. Assim, estes autores adotaram uma abordagem que considera os serviços sob três dimensões diferentes: entradas (equipamentos, reputação por qualidade, ambiente, entre outros), processos (qualidade da interação com clientes, incluindo cortesia, atenção e responsividade) e saídas (o resultado do serviço, como benefícios intangíveis relacionados à percepção dos clientes).

No presente trabalho, foram ponderadas as considerações relatadas acima em relação ao Servqual, e então foram selecionados aspectos da qualidade de serviços relacionados às dimensões relatadas por Johnson; Tsiros; Lancioni (1995). Com relação à entrada, foram selecionados itens referentes à reputação, equipamentos e ambiente físico. No tocante ao processo, foram selecionados os aspectos de atendimento cortês e amistoso, responsividade e atenção às necessidades. Finalmente, em relação às saídas, foram selecionados os aspectos atendimento às expectativas, atendimento às necessidades, confiabilidade do serviço e variabilidade do serviço.

\subsection{IMAGEM DA LOJA}

A imagem foi definida por Martineau (1958) como o modo como os consumidores definem a loja em sua mente, em parte pelas suas qualidades funcionais e em parte por um conjunto de atributos psicológicos. $\mathrm{O}$ autor afirma ainda que a capacidade de pagamento de certo consumidor fica em segundo plano na escolha da loja e que esta é influenciada principalmente pela imagem total que o cliente tem da 
loja, e que esta deve ser aceitável e atraente para seu estilo de vida.

Já Bloemer; Schroder (2002) definem imagem da loja como a soma de todos os atributos da loja percebidos pelos consumidores durante sua experiência dentro da loja.

A importância da imagem da loja no varejo foi evidenciada por Schiffman; Kanuk (2000), que afirmam que as lojas de varejo possuem imagem própria, a qual influencia a qualidade percebida dos produtos disponíveis na loja e dos serviços prestados, além das decisões dos consumidores sobre onde comprar.

Os aspectos emocional e racional da imagem foram observados por McGoldrick (2000), que defende que a imagem é formada pelo consumidor de forma seletiva, englobando uma combinação de material, factual e emocional. Além disso, este autor afirma que mesmo os atributos tangíveis, como preço e localização, podem ser analisados pelo consumidor de modo subjetivo, enquanto que os aspectos intangíveis, como atmosfera da loja, podem ser medidos por meio de atributos tangíveis, como música, iluminação, cores, etc.

Um importante aspecto da imagem da loja está relacionado ao mix ou sortimento de produtos disponibilizados na loja, sendo esta uma das principais decisões de uma empresa varejista (PARENTE, 2009). Neste aspecto, há também a possibilidade de inclusão de marcas próprias no mix de produtos do varejista, podendo gerar vantagens, como o fortalecimento da imagem do varejista e desenvolvimento da fidelidade do consumidor.

Outros aspectos como atmosfera e layout também tem ganhado importância, pois estão intimamente ligados à imagem da loja, podendo motivar os consumidores a passarem mais tempo dentro da loja. Parente (2009) define atmosfera como um sentimento psicológico que o varejista desenvolve no consumidor quando ele visita a loja, também entendida como personalidade da loja sob a ótica do consumidor.

A localização da loja também tem um papel crucial no desempenho de supermercados, já que a maior parte das vendas de uma loja vem de clientes que moram dentro de uma área geográfica pequena em torno da loja (PARENTE; KATO, 2001).

Com o crescimento da importância da imagem na análise do desempenho de estratégias de Marketing, tornou-se necessário buscar alternativas para mensurá-la. A escolha da técnica de mensuração da imagem deve buscar minimizar as fontes de erros e de distorção na pesquisa. Os principais métodos de mensuração são a escala de avaliação (incluindo escala de diferencial semântico, comparação numérica e de posicionamento de escala no gráfico), técnicas abertas e escalas multidimensionais (McGOLDRICK, 2000).

A complexidade na avaliação de imagem está relacionada ao fato de que o processo de percepção da imagem pode diferir entre diferentes consumidores. Schiffman; Kanuk (2000) afirmam que diferentes indivíduos podem estar sujeitos aos mesmos estímulos e mesmas condições aparentes, mas a maneira como cada um os reconhece, seleciona, organiza e interpreta é um processo individual baseado nas necessidades, valores e expectativas de cada pessoa.

A relação entre imagem e satisfação foi evidenciada por Bloemer; Ruyter (1998), que afirmam que a satisfação é construída, entre outras coisas, pela imagem da loja.

Em seu estudo, Bloemer; Schroder (2002) concluíram que um consumidor que tem uma percepção positiva em relação a uma loja em particular está mais propenso a ficar satisfeito com a loja do que um consumidor que possui uma percepção menos positiva da imagem da loja.

Portanto, considera-se necessário que as redes varejistas de supermercado considerem a importância da imagem da loja para seu desempenho, proporcionando aos consumidores uma experiência de compra agradável. 


\subsection{MARCA DO SUPERMERCADO}

A American Marketing Association (AMA, 2009) define marca como "um nome, termo, sinal, símbolo ou design, ou uma combinação de todos esses elementos, com o objetivo de identificar bens ou serviços de um vendedor e diferenciá-los de seus concorrentes".

Uma marca apresenta dimensões e características específicas e tem a função de diferenciar um produto de outros que visam satisfazer a mesma necessidade do consumidor. Essa diferenciação pode estar relacionada com aspectos racionais e tangíveis, ou seja, com o desempenho do produto, ou com os aspectos emocionais e intangíveis, ou seja, o que a marca representa para o consumidor (KELLER; MACHADO, 2006).

A marca é vista como uma vantagem competitiva, pois a reputação da marca gera demanda e atratividade de longo prazo. A imagem de qualidade superior e o valor agregado que a marca proporciona permitem o emprego de um preço superior. Além disso, quando uma marca é dominante no mercado, ela detém uma posição de referência e pode funcionar como uma barreira de entradas para os concorrentes (KAPFERER, 2003).

Existem dois tipos de marcas, as marcas dos produtos em geral, como a dos fabricantes e das marcas próprias, e as marcas do varejista. Este estudo tem como objetivo avaliar somente a influencia da marca do varejista na satisfação, e não inclui análises em relação às marcas dos produtos em si. A marca do varejista tem se tornado cada vez mais forte na cabeça dos consumidores, e por isso tem ajudado no direcionamento da decisão dos consumidores de onde comprar.

Conforme Kapferer (2003), a marca pode exercer oito diferentes funções junto aos consumidores, apresentadas no Quadro 1. É importante ressaltar que, conforme o autor, nem todas estas funções são exercidas simultaneamente por todas as marcas.

Quadro 1 - Funções da marca para os consumidores.

\begin{tabular}{|c|l|}
\hline Função & \multicolumn{1}{|c|}{ Benefício ao consumidor } \\
\hline De referência & $\begin{array}{l}\text { Ver claramente, situar-se em relação à produção setorial, } \\
\text { identificar rapidamente os produtos procurados. }\end{array}$ \\
\hline De praticidade & $\begin{array}{l}\text { Permitir ganho de tempo e de energia na recompra de produto } \\
\text { idêntico pela fidelidade. }\end{array}$ \\
\hline De garantia & $\begin{array}{l}\text { Segurança de encontrar uma qualidade estável em todos os } \\
\text { lugares e a todo estante. }\end{array}$ \\
\hline De otimização & $\begin{array}{l}\text { Segurança de comprar o melhor produto de sua categoria, com o } \\
\text { melhor desempenho para um uso específico. }\end{array}$ \\
\hline De personalização & $\begin{array}{l}\text { Sentir-se confortável com sua auto-imagem ou com a imagem que } \\
\text { é passada aos outros. }\end{array}$ \\
\hline De permanência & $\begin{array}{l}\text { Satisfação nascida da familiaridade e da intimidade das ligações } \\
\text { com uma marca que foi consumida durante anos e que ainda dura. }\end{array}$ \\
\hline Hedonista & $\begin{array}{l}\text { Satisfação ligada à estética da marca, seu design e suas } \\
\text { comunicações. }\end{array}$ \\
\hline
\end{tabular}

Fonte: Kapferer (2003, p. 24).

De acordo com Kotler; Keller (2006), seria possível que concorrentes copiassem com facilidade processos de fabricação e design, mas as impressões positivas dos clientes, geradas principalmente pelas atividades de marketing e experiências de consumo, dificilmente são equiparadas, evidenciando que a 
gestão de marcas pode ser o meio mais poderoso de se obter vantagem competitiva, principalmente no varejo, considerando-se que é comum o fato de que diferentes redes varejistas geralmente vendem as mesmas mercadorias dentro de suas lojas e possuem design e serviços semelhantes, o que torna difícil a obtenção de vantagem competitiva de longo prazo neste segmento (LEVY; WEITZ, 2000).

\section{ASPECTOS METODOLÓGICOS}

O presente trabalho teve como objetivo avaliar a satisfação de consumidores supermercadistas de Ribeirão Preto, analisando de forma integrada a influência da qualidade percebida, imagem da loja e marca do supermercado para a formação desta satisfação.

Foi desenvolvida uma pesquisa quantitativa, que, segundo Richardson (1999), é um tipo de pesquisa caracterizada por utilizar parâmetros quantificáveis, tanto para a coleta de informações quanto para o tratamento dos dados empregando-se técnicas estatísticas.

O método de coleta de dados utilizado foi o levantamento de campo, por meio da aplicação de questionários. Segundo Malhotra (2005), levantamentos de campo são utilizados quando a pesquisa envolve entrevistas com um grande número de pessoas e uma série de perguntas.

Deve-se destacar que este trabalho não buscou analisar o desempenho de redes supermercadistas específicas, mas sim os elementos influenciadores da satisfação do consumidor supermercadista em geral. Portanto, os entrevistados foram solicitados a responder as questões de acordo com as características do supermercado onde eles estavam mais acostumados a efetuarem suas compras. Além disso, foi solicitado no início do questionário que o respondente destacasse o nome do supermercado onde estivesse mais acostumado a comprar, para que, assim, tivesse em mente apenas um supermercado, e não todos os supermercados que conhece.

A amostra foi composta por 235 pessoas, abordadas em ambientes como faculdades e alguns pontos comerciais, todos situados na cidade de Ribeirão Preto. Deve-se ressaltar que, na coleta de dados, foi utilizado o método de amostragem por conveniência, o que, se por um lado facilita a coleta de dados, por outro, torna-se uma limitação a ser observada caso haja intenção dos autores em generalizar os resultados obtidos (COOPER; SCHINDLER, 2003).

O questionário desenvolvido pelos autores utilizou-se da escala de Likert de cinco pontos, sendo esta amplamente utilizada em pesquisas, exigindo que os entrevistados indiquem um grau de concordância ou discordância em relação a cada uma dentre uma série de afirmações sobre o objeto de estudo. Segundo Malhotra (2005), a escala de Likert possui várias vantagens, dentre elas a facilidade de construção e posterior aplicação, além de que os entrevistados entendem rapidamente como utilizá-la. O Quadro 2 lista todas as questões de pesquisa, divididas de acordo com o respectivo conceito com o qual estão relacionadas.

Quadro 2 - Questões x conceito relacionado

(Continua)

\begin{tabular}{|c|l|}
\hline Conceito & \multicolumn{1}{c|}{ Questão } \\
\hline & Os produtos vendidos são de qualidade. \\
& Os funcionários são cordiais e amigáveis. \\
Os funcionários respondem perguntas corretamente. & Eu recebi os serviços que esperava. \\
percebida & Os serviços são confiáveis. \\
& O serviço efetuado atendeu às minhas expectativas. \\
& As frutas, legumes e verduras vendidos são de qualidade. \\
& O atendimento é atencioso. \\
& As facilidades físicas são muito boas. \\
& Os equipamentos e móveis são modernos. \\
\hline
\end{tabular}

Nucleus, v.9, n.2, out.2012 


\begin{tabular}{|c|l|}
\hline \multirow{5}{*}{ Imagem da } & $\begin{array}{l}\text { O ambiente é agradável. } \\
\text { A localização é conveniente. } \\
\text { A loja é bem freqüentada. }\end{array}$ \\
O o sortimento de produtos é muito bom. \\
Os preços são muito bons. \\
As promoções oferecidas são muito boas. \\
A atmosfera da loja é muito boa. \\
O horário de funcionamento é conveniente. \\
A limpeza e manutenção são muito boas.
\end{tabular}

Fonte: Elaborado pelos autores (2010).

Com relação à análise dos dados, foi utilizada a análise multivariada, a qual, de acordo com Hair Junior et al. (2006,), refere-se a todos os métodos estatísticos que analisam simultaneamente múltiplas medidas em cada indivíduo ou objeto sob investigação.

A técnica estatística utilizada para análise dos dados coletados foi a regressão múltipla, a qual, segundo Hair Junior et al. (2006), é uma técnica usada para analisar a relação entre uma variável dependente (satisfação) e outras variáveis independentes. O objetivo da aplicação desta técnica foi desenvolver uma equação que relacionasse as variáveis qualidade, imagem e marca com a satisfação dos clientes supermercadistas, permitindo aos pesquisadores analisar as relações existentes entre estas variáveis.

Finalmente, cabe pontuar que, para desenvolver as análises estatísticas acima, foi utilizado o software estatístico SPSS for Windows.

\section{ANÁLISE E DISCUSSÃO DOS RESULTADOS}

Em relação à amostra de pesquisa, cabe destacar que esta foi composta por 235 pessoas, sendo $58 \%$ do sexo masculino e $42 \%$ do sexo feminino. Além disso, $72,3 \%$ dos respondentes têm entre 20 e 24 anos, sendo que a faixa de idade dos entrevistados variou entre 17 e 43 anos.

Inicialmente, foi desenvolvida uma análise de algumas estatísticas descritivas, com o intuito de entender os dados coletados. Cada item do questionário aplicado recebeu uma pontuação que variou de 1 (discordo totalmente) até 5 (concordo totalmente), sendo que a pontuação máxima (soma de todas as respostas) que cada item poderia receber seria 1.175 pontos (caso todas as 235 pessoas assinalassem o valor 5 para o item).

Dentre os 28 itens analisados no questionário (ver quadro dois), os itens que receberam maior pontuação foram localização (1.016), qualidade dos produtos vendidos (1.013), reputação (1.007) e 
horário de funcionamento (1.002). Neste caso, estes foram os itens mais bem avaliados pelos clientes em relação ao supermercado onde os mesmos realizam a maior parte de suas compras.

A partir destas informações, é possível perceber a crescente preocupação destes varejistas com a conveniência de seus consumidores, já que o tanto o horário de atendimento quanto a localização da loja estão relacionados a facilidades e maior conveniência para os clientes.

Além disso, deve-se destacar a elevada pontuação relacionada à qualidade dos produtos vendidos, o que evidencia que os supermercadistas estão preocupados em oferecer aos consumidores um sortimento de produtos que atenda às expectativas de qualidade dos clientes.

Também se deve ressaltar a importância que os supermercadistas estão dando para sua reputação, já que a grande maioria dos consumidores concordou que o supermercado escolhido para as compras possuía uma boa reputação no mercado. Neste sentido, a gestão da imagem e marca mostram-se relevantes no cenário atual.

Por outro lado, os itens que receberam as menores pontuações foram satisfação com a internet (446), satisfação com feiras (674), preços (740) e promoções (762). Deve-se pontuar que estes foram os itens considerados menos satisfatórios para os clientes supermercadistas que responderam a pesquisa.

As baixas pontuações alcançadas pela satisfação dos clientes com feiras livres e com as compras realizadas pela internet, quando comparadas com a satisfação com supermercados, mostram a importância que o formato de varejo denominado supermercado ganhou na sociedade moderna, conforme ressaltado por vários autores citados no referencial teórico deste trabalho.

Entretanto, deve-se destacar que os consumidores pesquisados mostraram-se insatisfeitos com a política de preços e promoções desenvolvida pelos supermercadistas modernos, o que pode ser uma das causas para a baixa satisfação geral dos consumidores supermercadistas, que obteve média 3,6 e pontuação total de apenas 847 , sendo que a satisfação geral dos clientes supermercadistas ficou entre os itens menos pontuados.

Depois de uma análise inicial das estatísticas descritivas, passou-se para a análise de regressão múltipla. Deve-se ressaltar que foram feitos os testes de Skewness; Kurtosis, que medem se as variáveis estudadas possuem uma distribuição normal, já que, em caso negativo, a regressão múltipla pode ter seus resultados comprometidos. Os resultados dos dois testes apontaram que todas as variáveis da pesquisa tendem para uma distribuição normal, validando a aplicação da técnica de regressão sobre os dados.

A análise de regressão múltipla desenvolvida forneceu oito modelos diferentes, capazes de explicar a satisfação geral dos clientes supermercadistas pesquisados.

Dos oito modelos fornecidos, os autores optaram por trabalhar com o modelo seis, já que os modelos sete e oito pouco colaboram para aumentar o poder de explicação do modelo final em relação à satisfação geral dos consumidores supermercadistas.

O modelo seis possui um $\mathrm{R}^{2}$ ajustado de 0,583 , o que indica que $58,3 \%$ da satisfação dos clientes supermercadistas participantes desta pesquisa é explicada pelas variáveis que compõem o modelo selecionado.

O modelo seis pode ser representado da seguinte forma:

$$
\text { Satisfação geral }=0,114 X_{1}+0,241 X_{2}+0,216 X_{3}+0,181 X_{4}+0,186 X_{5}+0,202 X_{6}-0,606
$$

Sendo:

$\mathrm{X}_{1}$ - qualidade do ambiente da loja;

$\mathrm{X}_{2}$ - percepção de que os serviços esperados foram recebidos;

$\mathrm{X}_{3}$ - identificação do cliente com a marca do supermercado; 
$\mathrm{X}_{4}$ - percepção de que as promoções são boas;

$\mathrm{X}_{5}$ - percepção de que a atmosfera da loja é agradável;

$\mathrm{X}_{6}$ - qualidade dos produtos vendidos.

Analisando o modelo seis, é possível verificar a importância dos três conceitos pesquisados na satisfação dos consumidores supermercadistas, já que a qualidade dos produtos vendidos e a percepção de que os serviços esperados foram recebidos estão relacionadas à (1) qualidade percebida; a identificação do cliente com a marca do supermercado está relacionada com (2) a marca do supermercado; e a atmosfera da loja, as promoções e o ambiente da loja estão relacionados com (3) a imagem que o supermercadista forma na mente do consumidor.

Além disso, conforme citado no referencial teórico do trabalho, é possível confirmar a influência das experiências de consumo dos clientes varejistas na formação de sua satisfação, na medida em que todos os itens presentes no modelo analisado estão relacionados com as variáveis ligadas às experiências de consumo dos clientes no varejo.

Em relação à variável qualidade dos produtos vendidos, é possível perceber que, ao mesmo tempo em que os varejistas estão conscientes de que o sortimento de produtos disponibilizado aos clientes deve ter alta qualidade (este item recebeu uma boa avaliação dos consumidores pesquisados), este item torna-se extremamente importante para a satisfação dos consumidores supermercadistas.

A importância da variável ligada à percepção dos clientes de que os serviços esperados foram recebidos está relacionada ao fato de que a satisfação dos consumidores está, em grande parte, vinculada à percepção de que as expectativas foram atendidas, conforme a própria definição de satisfação apresentada anteriormente.

A importância da qualidade do ambiente e da atmosfera da loja para a formação da satisfação dos consumidores supermercadistas confirma as constatações de autores como Bloemer; Ryuter (1998), e pode ser explicada pelo fato de que, quando os clientes sentem-se confortáveis dentro da loja, estes tendem a manter uma atitude positiva em relação ao supermercado, o que favorece a formação da satisfação.

As promoções desenvolvidas pelo varejista também se mostraram importantes, e vão ao encontro das afirmações de Grewal; Levy; Kumar (2009), que defendem que o nível de preços (incluindo as

promoções desenvolvidas) praticado pelos varejistas influencia na qualidade das experiências de consumo vivenciadas pelos consumidores e que estas influenciam na satisfação geral dos clientes no varejo. Entretanto, deve-se ressaltar a baixa pontuação alcançada por esta variável, o que mostra que os supermercadistas modernos devem se atentar mais para esta variável do composto varejista.

Finalmente, em relação à importância da identificação do cliente com a marca do varejista para a satisfação, pode-se confirmar as constatações de Kapferer (2003), sendo que, neste caso, em que os clientes buscam se identificar com a marca do supermercado, pode-se afirmar que a marca assume as funções de personalização e permanência, quando o cliente busca uma imagem capaz de projetar sua autoimagem e que esteja ligada ao seu modo de ser.

Este último item também merece uma ressalva, já que a identificação dos clientes com a marca do supermercadista recebeu a quinta menor pontuação geral (769), o que mostra que os varejistas atuais devem se esforçar mais para conhecer os valores dos consumidores, de modo a favorecer a projeção no mercado de uma marca que realmente esteja vinculada aos valores dos clientes. 


\section{CONSIDERAÇÕES FINAIS}

Este trabalho teve como objetivo avaliar a satisfação de consumidores supermercadistas de Ribeirão Preto, analisando de forma integrada a influência da qualidade percebida, imagem da loja e marca do supermercado para a formação desta satisfação.

Para atingir este objetivo, foi elaborado um questionário com base no referencial teórico previamente pesquisado, aplicado posteriormente em uma amostra de 235 pessoas na cidade de Ribeirão Preto.

Dentre as constatações desta pesquisa, foi possível confirmar a importância da imagem da loja, da marca do supermercadista e da qualidade percebida na formação da satisfação dos consumidores supermercadistas.

Deve-se ressaltar, entretanto, que os consumidores pesquisados não apontaram um nível de satisfação atual muito elevado, o que evidencia a necessidade de mudanças por parte dos supermercadistas modernos, principalmente nos quesitos relacionados a preços, promoções e identidade entre os clientes e a marca do supermercado. Neste sentido, destacam-se aqui alguns temas a serem explorados em pesquisas futuras, de modo a favorecer com que os supermercadistas melhor se adaptem às expectativas de seus consumidores.

Outro ponto a ser destacado é a importância de se conhecerem as expectativas dos consumidores em relação aos serviços esperados, já que o sentimento de que os serviços esperados foram recebidos mostrou-se bastante importante para a formação da satisfação dos consumidores no varejo.

A atmosfera e o ambiente da loja também se mostraram essenciais para a satisfação dos consumidores supermercadistas, destacando-se a necessidade, por parte destes varejistas, de desenvolverem um ambiente de loja moderno e, ao mesmo tempo, confortável, fornecendo aos clientes experiências de consumo mais agradáveis.

Além disso, deve-se ressaltar a constatação de que a satisfação do consumidor no varejo supermercadista não é um conceito linear, ou seja, a satisfação deste consumidor sofre influência de uma série de fatores, o que vem ao encontro dos estudos de Verhoef et al. (2009), Meyer; Schwager (2007), Gentile; Spiller; Noci; (2007) Grewal; Levy; Kumar (2009), que destacam a importância e simultaneidade de todos os elementos de interação entre o varejista e o cliente para a formação da satisfação deste último, demonstrando-se aqui a relevância do conceito de experiências de consumo abordado neste artigo.

Dentre as limitações deste trabalho, deve-se citar a amostra de pesquisa, coletada apenas na cidade de Ribeirão Preto e com característica predominantemente jovem (entre 20 e 24 anos). Além disso, o fato de que a seleção dos elementos da amostra não foi aleatória compromete a capacidade de generalização das constatações do estudo. Assim, como sugestão para pesquisas futuras, podem ser desenvolvidos novos estudos, utilizando-se as mesmas questões e conceitos presentes neste trabalho, porém em outras regiões do país, com uma amostra mais diversificada.

Finalmente, fica a sugestão para que este estudo seja ampliado a outros segmentos do varejo, extrapolando-se o segmento supermercadista; e que novas variáveis sejam testadas, de maneira a consolidar uma visão holística acerca da satisfação do consumidor no varejo.

\section{REFERÊNCIAS}

ALEXANDER, N.; SILVA, M. L. Emerging markets and the internationalization of retailing: The brazilian experience. International Journal of Retail \& Distribution Management, New York, v.30, n.6/7, 2002. 
AMA. American Marketing Association. Resource Library: Dictionary. Disponível em: <http://www.marketingpower.com/_layouts/Dictionary.aspx?dLetter=B >. Acesso em 10 nov. 2009.

ABRAS. Associação Brasileira de Supermercados . SuperHiper Panorama 2010. Disponível em: < http://www.abrasnet.com.br/superhiper/panorama/conteudos/o-setor/>. Acesso em 10 mar. 2010.

BLOEMER, J.; SCHRODER, G. Store Satisfaction and store loyalty explained by customer and store related factors. Journal of Consumer Satisfaction, Dissatisfaction and Complaining Behavior. v. 15, p. 68-80. 2002.

BLOEMER, J.; RUYTER, K. On the relationship between store image, store satisfaction and store loyalty. European Journal of Marketing. v. 32, n. 5/6, p. 499-513. 1998.

COOPER, D. R.;SCHINDLER, P. S. Métodos de pesquisa em administração. 7. ed. Porto Alegre: Editora Bookman, 2003.

CZINKOTA, M. R. et al. Marketing: As melhores práticas. Porto Alegre: Bookman, 2001.

ENGEL, J. F.; BLACKWEL, R. D.; MINIARD, P. W. Comportamento do consumidor. 9. ed. São Paulo: Pioneira Thomson Learning, 2005.

GENTILE, C.; SPILLER, N.; NOCI, G. How to sustain the customer experience: An overview of experience components that co-create value with the customer. European Management Journal 25, p. 395-410, 2007.

GREWAL, D.; LEVY, M.; KUMAR, V. Customer experience management in retailing: An organizing framework. Journal of Retailing 85, p. 1-14, 2009.

HAIR JUNIOR, J.F. et al. Análise multivariada de dados. 5. ed. Porto Alegre: Bookman, 2006.

JOHNSON, R. L.; TSIROS, M.; LANCIONI, R. A. Measuring service quality: a systems approach. Journal of Services Marketing, MCB University. v. 9, n.5, p. 6-19. 1995.

KAPFERER, J. N. As marcas, capital da empresa. 3. ed. Porto Alegre: Bookman, 2003.

KELLER, K. L.; MACHADO, M.. Gestão estratégica de marcas. São Paulo: Pearson Prentice Hall, 2006.

KOTLER, P.; KELLER, K. L. Administração de Marketing. 12. ed. São Paulo: Pearson Prentice Hall, 2006.

LARÁN, J. A.; ESPINOZA, F. S. Consumidores Satisfeitos, e Então? Analisando a Satisfação como Antecedente da Lealdade. RAC - Revista de Administração Contemporânea. Vol. 8, n. 2, p. 51-70. 2004.

LAS CASAS, A. L. Estratégias de Marketing para Varejo: inovações e diferenciações estratégicas que fazem a diferença no marketing de varejo. São Paulo: Novatec Editora, 2007.

LEVY, M.; WEITZ, B. A. Administração de varejo. 3. ed. São Paulo: Atlas, 2000.

MALHOTRA, N. K. Introdução à pesquisa de marketing. São Paulo: Pearson Prentice Hall, 2005.

MARTINEAU, P.. The personality of the retail store. Harvard Business Review, v. 36. Jan.-feb. p. 4755. 1958.

McGOLDRICK, P. J. Retail marketing. London: McGraw-Hill, 2000. 
MEYER, C.; SCHWAGER, A. Understanding customer experience. Harvard Business Review, p. 117126, feb. 2007.

MOURA, T. L.; SILVA, A. L.; VIANA, A. B. Formatos de varejo: o caso do consumidor de alimentos. 2005. In: ANGELO, C.F.; SILVEIRA, J.A.G. Varejo competitivo. 10 ed. São Paulo: Saint Paul, 2005.

OLIVER, R. L. Satisfaction: a behavioral perspective on the consumer. New York: McGraw Hill, 1997.

PARASURAMAN, A.; ZEITHAML, V. A.; BERRY, L. L. Five imperatives for improving service quality. Sloan Management Review, Cambridge. v. 31, n.4, p. 29-3. Summer 1990.

PARENTE, J.. Varejo no Brasil: Gestão e estratégia. 8. reimpr. São Paulo: Atlas, 2009.

PARENTE, J.; KATO H. T. Área de influência: um estudo no varejo de supermercados. RAE - Revista de Administração de Empresas. Vol 41, n. 2, p. 46-53. 2001.

RICHARDSON, R. J. Pesquisa social: métodos e técnicas. São Paulo: Atlas, 1999.

ROJO, F. J. G. Supermercados no Brasil: qualidade, marketing de serviços, comportamento do consumidor. São Paulo: Atlas, 1998.

SAAB, W. G.; GIMENEZ, L. C. Supermercados no Brasil: o movimento das grandes empresas. BNDES Setorial, n. 22, Rio de Janeiro, Dez. 2000.

SANTOS, A. M.; GIMENEZ, L. C. P. Reestruturação do comércio varejista e de supermercados. BNDES Setorial. Rio de Janeiro: BNDES, 1999.

SCHIFFMAN, L. G.; KANUK, L. L. Consumer Behavior. 7. ed. New Jersey. Prentice Hall, 2000.

SILVIA, L. A. Atitude do consumidor em relação às marcas próprias de supermercados: um estudo exploratório. 2009. 235 p. Dissertação (Mestrado em Administração de Organizações). Faculdade de Economia, Administração e Contabilidade, Universidade de São Paulo, Ribeirão Preto.

SIROHI, N. et al. Model of consumer, perceptions and store loyalty intentions for a supermarket retailer. Journal of Retailing, v. 74, n.2, p. 223-245, 1998.

VERHOEF, P. C et al. Customer experience creation: Determinants, dynamics and management strategies. Journal of Retailing, v.85, p. 31-41, 2009.

YI, Y. A critical review of consumer satisfaction, working paper 604, University of Michigan, School of Business, An Arbor, Michigan, 1989.

ZEITHAML, V. A. Consumer perceptions of price, quality, and value: a means-end model of synthesis of evidence. Journal of Marketing. v. 52, n. 3, p. 2-22. 1988. 